\title{
O TEATRO COMO COMPONENTE CURRICULAR E A APRENDIZAGEM COOPERATIVA NO CONTEXTO DAS AÇÕES DO PROGRAMA FOCCO
}

\section{THEATER AS A CURRICULAR COMPONENT AND COOPERATIVE LEARNING IN THE CONTEXT OF ACTIONS OF THE FOCCO PROGRAM}

\author{
Suzely Ferreira da Silva ${ }^{1}$ \\ Ângela Maria Santana ${ }^{2}$ \\ Maria do Rosário Soares Lima ${ }^{3}$ \\ Kelli Cristina Aparecida Munhoz Moreira ${ }^{4}$
}

Recebido: $15 / 10 / 2020$

Aceito: 28/12/2020

Resumo: Este texto relata uma experiência que versa sobre o desenvolvimento das ações do curso de extensão $O$ Teatro como Componente Curricular e a Aprendizagem Cooperativa no Contexto das Ações do Programa Focco, realizado por um grupo de bolsistas do Programa de Formação de Células Cooperativa de Aprendizagem (FOCCO) da Universidade do Estado de Mato Grosso Carlos Alberto Reyes Maldonado implementado pelo Câmpus Universitário do Médio Araguaia Dom Pedro Casaldáliga. Tendo como objetivo apresentar estratégias para o fortalecimento das células de aprendizagem cooperativa (grupos de estudos) sob a compreensão de que a organização das atividades que cercam o teatro é compatível com os princípios metodológicos do Programa FOCCO a partir do desenvolvimento das habilidades para trabalhar em grupo e trocar experiências entre aluno-aluno-professor-aluno. E assim, reconhecer a importância do protagonismo estudantil por meio do processo de construção de políticas educacionais. Esse curso é oferecido na modalidade ensino remoto, com encontros virtuais pela plataforma Google Meet, discussões em um grupo de WhatsApp e o compartilhamento de material de leitura e via Facebook, Instagram e Youtube. Para o desenvolvimento desse artigo recorremos aos princípios da pesquisa-ação sob viés da metodologia qualitativa a partir do uso de entrevistas, aplicação de formulários online e outras fontes documentais. Adotamos como referencial teórico as concepções dos autores Arroyo (2013), Candau (2011), Vygotsky (1999) Courtney, R. (1980) entre outros. Enquanto resultado podemos sinalizar que há uma aceitação por parte da maioria dos cursistas que de fato o teatro é um recurso metodológico estratégico para o desenvolvimento de práticas de ensino, sobretudo no que se refere ao desenvolvimento das habilidades para o trabalho em equipe e também da comunicação oral e corporal. Há também uma indicação que o teatro deve ser incorporado ao currículo escolar como uma disciplina ou ao menos como sendo conteúdo obrigatório sob a lógica de ser tema transversal ou interdisciplinar.

\footnotetext{
1 Graduanda em Filosofia pela Universidade do Estado de Mato Grosso (UNEMAT). E-mail: suzely.silva@unemat.br

2 Graduanda em Filosofia pela Universidade do Estado de Mato Grosso (UNEMAT). E-mail: angela.roman@unemat.br

${ }^{3}$ Mestra em História pela Universidade Federal de Mato Grosso (UFMT). E-mail: lima.maria@unemat.br

${ }^{4}$ Doutora em Ecologia Aplicada pela Universidade de São Paulo (USP). E-mail: kelli.munhoz@unemat.br
} 
Palavras-chave: FOCCO; Teatro; Extensão; Aprendizagem cooperativa.

Abstract: This text reports an experience that deals with the results obtained with the development of the actions of the extension course The Theater as a Curricular Component and Cooperative Learning in the Context of the Focco Program Actions, developed by the Fellows of the Cooperative Learning Cell Training Program (FOCCO). The program aims to present strategies for strengthening cooperative learning cells (study groups) under the understanding that the organization of activities surrounding the theater is compatible with the methodological principles of the FOCCO Program from the development of skills to work in groups and exchange of experiences between student teacher. And thus, recognize the importance of student protagonist and the process of building educational policies. This course offered is in the form of remote teaching, with virtual meeting by the Google Meet platform, discussions in a WhatsApp group and the sharing of reading and production material via Facebook, Instagram and Youtube. For the development of this article, we used the principles of qualitative methodology from the use of interviews, forms and other documentary sources. We adopted as theoretical reference the conceptions of the authors ARROYO (2013), CANDAU (2011), VYGOTSKY (1999) COURTNEY, R. (1980) among others. As a result, we can point out that there is an acceptance by most students that theater is in fact a strategic methodological resource for the development of teaching practices, especially with regard to the development of skills for teamwork and also oral and body communication. There is also an indication that the theater be should incorporated into the school curriculum as a discipline.

Keywords: FOCCO. Theater. Extension. Cooperative learning.

\section{Introdução}

O Programa FOCCO foi criado pela Universidade do Estado de Mato Grosso (UNEMAT) no ano de 2012, com a finalidade de trabalhar o ensino-aprendizagem através de células/grupos de estudos, com objetivo de melhorar a autoestima dos estudantes para que houvesse aumento na taxa de permanência e aprovação nos cursos de graduação e ao mesmo tempo estimular profissionais capacitados a trabalharem em equipes. Dentre outras funções, os bolsistas desse programa têm que criar células de estudos e atividades de extensão universitária de modo que a aprendizagem cooperativa possa ser apresentada também ao contexto da educação básica.

Desse modo, no mês de agosto do ano de 2020, um grupo de acadêmicos (bolsistas FOCCO), graduandos em Filosofia pelo Campus Universitário do Médio Araguaia Dom Pedro Casaldáliga - Núcleo Pedagógico de Vila Rica- MT, assumiram em conjunto com professores da coordenação local deram início ao curso de extensão - O Teatro como 
Componente Curricular e a Aprendizagem Cooperativa no Contexto das Ações do Programa Foco. Esse curso buscou estratégias para a dinâmica de fortalecimento das células de aprendizagem cooperativa (grupos de estudos) sob a compreensão que:

[...], o diálogo é uma exigência existencial. E, se ele é o encontro em que se solidarizam o refletir e o agir de seus sujeitos endereçados ao mundo a ser transformado e humanizado, não pode reduzir-se a um ato de depositar ideias de um sujeito no outro, nem tampouco tornar-se simples troca de ideias a serem consumidas pelos permutantes, (FREIRE, 2005, p. 91).

Assim, a luz da concepção de Paulo Freire (2005), afirmamos que a organização das atividades que cercam o teatro é extremamente compatível com os princípios e os elementos da aprendizagem cooperativa, tal como estão incorporados nas diretrizes metodológicas do FOCCO, quando considerado o incremento das habilidades para trabalhar em grupo, a construção de redes de solidariedade e amizades desencadeadas pelo hábito de trocar experiências seja na condição de aluno ou de professores. Essas redes tornam-se mais significativa quando construídas através do protagonismo estudantil.

A metodologia de trabalho adotada para o desenvolvimento do curso configura-se como sendo uma estratégia de ensino e aprendizagem direcionada à modalidade de ensino remoto, visando adequar as ações vinculadas ao FOCCO, ao formato das diretrizes do PLSE - Período Letivo Suplementar Excepcional implementada pela PROEG-pró-reitora de ensino de graduação. Assim, o curso foi pensado para que pudéssemos realizar as ações que haviam sido planejadas antes da situação de pandemia e isolamento social. Pois devido à pandemia da Covid-19, enfrentada neste ano (2020) fez-se necessário a criação de novas estratégias que nos orientassem o saber lidar com os desafios do fazer docente e discente.

Desse modo, foi preciso a construção de novas referências metodológicas para a prática do teatro em sala de aula, uma vez que desde o início do curso a proposta assegurava como objetivo principal, a melhoria do processo de aprendizagem a partir do desenvolvimento de estratégias que fizessem com que os cursistas desenvolvessem habilidades psicomotoras, corporal e de linguagem através do teatro enquanto conteúdo ou recurso metodológico.

Para tanto, foram aplicadas metodologias possíveis para o ensino virtual. As aulas aconteciam via a plataforma Google Meet, por meio de rodas de leituras e diálogos, palestras, oficinas sobre as atividades relacionadas à prática de jogos teatrais, preparação (ensaios), 
movimento corporal/vocal do ator (corpo cênico), prática de organização de cenários e iluminação, enquanto elementos integradores entre si e ao espetáculo (princípios estéticos e técnicos da cenografia), dentre outros.

Consideramos ser importante ainda, destacar que o método de aprendizagem cooperativa além de se respaldar é estruturado a partir da formação de pequenos grupos de alunos, em que "[...] o objetivo é buscar elevar o nível de aprendizagem dos componentes das equipes, onde todos formam um grupo em busca de um objetivo comum [...], (PINHO, FERREIRA E LOPES, 2009, p. 916). Ou seja, a aprendizagem cooperativa busca a responsabilidade do cursista, não diz somente a respeito do seu trabalho individual, mas do trabalho de todo o grupo em que o sucesso de um componente, depende do sucesso de outro.

Dessa forma, o teatro é trabalhado ora como conteúdo e ora como recurso/estratégia didática, compreendendo sua inserção nos projetos pedagógicos com o objetivo de praticar o pensamento crítico por meio das diversas formas artísticas, buscando aprimorar as habilidades através das células/grupos de estudos.

Consideramos ser importante destacar que a nossa relação com a prática de teatro, enquanto um recurso didático e conteúdo curricular, deu-se a partir de nossas experiências enquanto acadêmicas do curso de Licenciatura em Filosofia, quando passamos a trabalhar com o teatro em apresentação de conteúdo/temas de teor complexos, sob o aspecto teórico ou quando se tratava de temas que em geral as pessoas não gostam de falar sobre.

E com o passar do tempo percebemos que o trabalho com o teatro, na condição de componente curricular, requeria conhecimento das técnicas, da história, das categorias/tendências/estilos, bem como de referencial teórico que constituem o teatro como sendo uma área de conhecimento. Foi daí que surgiu a ideia de realizarmos uma célula para estudarmos o teatro, e, diante do contexto de isolamento social, resolvemos reconfigurar a célula tornando-a em um curso de extensão pela modalidade ensino remoto.

\section{0 teatro como componente curricular e a aprendizagem cooperativa no ensino remoto}

Conforme já sinalizado anteriormente, pensar ações do curso de extensão - $\mathrm{O}$ Teatro como componente curricular e a aprendizagem cooperativa no contexto das ações do Programa FOCCO, remeteu-nos a condição de fazer valer o protagonismo estudantil sob a 
lógica do desenvolvimento de atividades práticas no que se referem ao método de aprendizagem cooperativa ao criarmos uma rede de solidariedade e parceria com professores e profissionais da área do teatro, os quais atuaram como ministrante de oficinas e palestras nos ajudando a compreender o processo de evolução das artes cênicas no tempo e no espaço, bem como a relação do teatro com os movimentos sociais, a cultura "popular" e na identificação dos grupos teatrais existente no Território Araguaia - Xingu (micro região norte do estado de Mato Grosso).

Ressalvamos que segundo os autores Pinho, Ferreira e Lopes (2009, p. 915), o método de aprendizagem cooperativa proporciona "[...] o desenvolvimento de competências não só acadêmica, como também social, adquire importância relevante, pois é fundamental que os alunos aprendam e sejam formados para saberem se relacionar e cooperar com os outros $[\ldots] "$.

A luz da concepção dos autores buscamos organizar as ações desse curso, sob a lógica de colocarmos como público alvo alunos e professores das escolas de educação básica, acadêmicos e pessoas ligadas às atividades culturais. Tendo como referência o protagonismo estudantil, o que significa dizer, que os cursistas de modo geral foram a "voz" que conduziram o nosso planejamento para a realização desse curso.

Nessa perspectiva, buscamos compreender o conceito de protagonismo juvenil a partir da concepção de Costa (2001), o qual diz que:

[...] o termo Protagonismo Juvenil, enquanto modalidade de ação educativa é a criação de espaços e condições capazes de possibilitar aos jovens envolverem-se em atividades direcionadas à solução de problemas reais, atuando como fonte de iniciativa, liberdade e compromisso, (COSTA 2001, p. 179).

Logo, pensar o protagonismo juvenil/estudantil é também refletir sobre o papel da aprendizagem cooperativa, pois na medida que trabalhamos a Célula/Curso de teatro acreditamos que de algum modo contribuímos com o fortalecimento da nossa própria rede de solidariedade e amizades tanto entre nós acadêmicos como entre os professores e os alunos das escolas de educação básica, os quais são de municípios diferentes, uma vez que melhorarmos as nossas condições de comunicação não só no âmbito acadêmico, mas também com o mundo que nos rodeia. Assim, estamos também tentando nos reconhecermos enquanto agentes protagonistas do processo educacional, nos enxergando como objeto em 
construção desse meio social e ao mesmo tempo fortalecendo as ações da universidade pública por meio da política de extensão.

Para isso, as atividades foram construídas em parcerias com os nossos professores e palestrantes de outras instituições como a Secretaria de Estado de Educação de Mato Grosso, o Instituto Federal de Mato Grosso, alguns segmentos de movimentos sociais e rede privada, de modo que pudemos discutir com os profissionais da educação básica a importância de incluir os cinco elementos da aprendizagem cooperativa como sendo um princípio do planejamento coletivo e da organização das estratégias de ensino e aprendizagem, em que o proposito seja a incorporação da "interdependência positiva; responsabilidade individual; interação "frente a frente", permitindo o desenvolvimento de competências sociais, desenvolvimento de competências interpessoais e grupais

As atividades foram desenvolvidas partir de rodas de leituras, diálogos e desenvolvimento de oficinas práticas de jogos teatrais e dinâmica de improvisação sob a perspectiva da linguagem artística, a construção de análises acerca de peças teatrais, tomando como referência a dramaturgia e sua relação com a literatura, a filosofia e a história. E houve também momento de preparação (ensaios) de movimentos corporal/vocal (corpo cênico), de organização de cenários e iluminação. Tendo como proposito compreendermos os elementos integrados entre si e ao espetáculo (princípios estéticos e técnicos da cenografia), bem como a interpretação a partir da perspectiva estética da encenação, sob o viés do processo de montagem cênico teatral); dentre outras atividades. A seguir mostramos algumas figuras dos dias de encontros virtuais.

Figura 01-palestra sobre o teatro e poesia-03 encontros

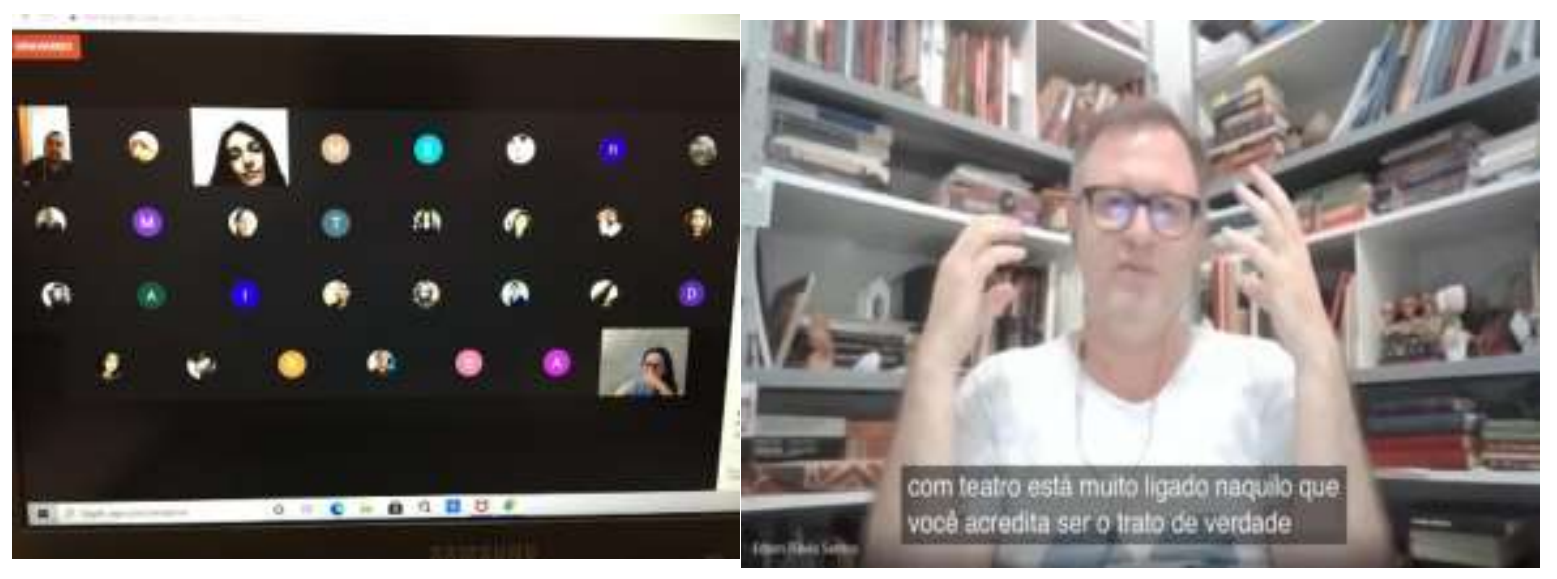

Fonte: arquivo das autoras, setembro de 2020. 
Figura 02-palestra sobre jogos teatrais e dinâmicas de improvisação-02 encontros

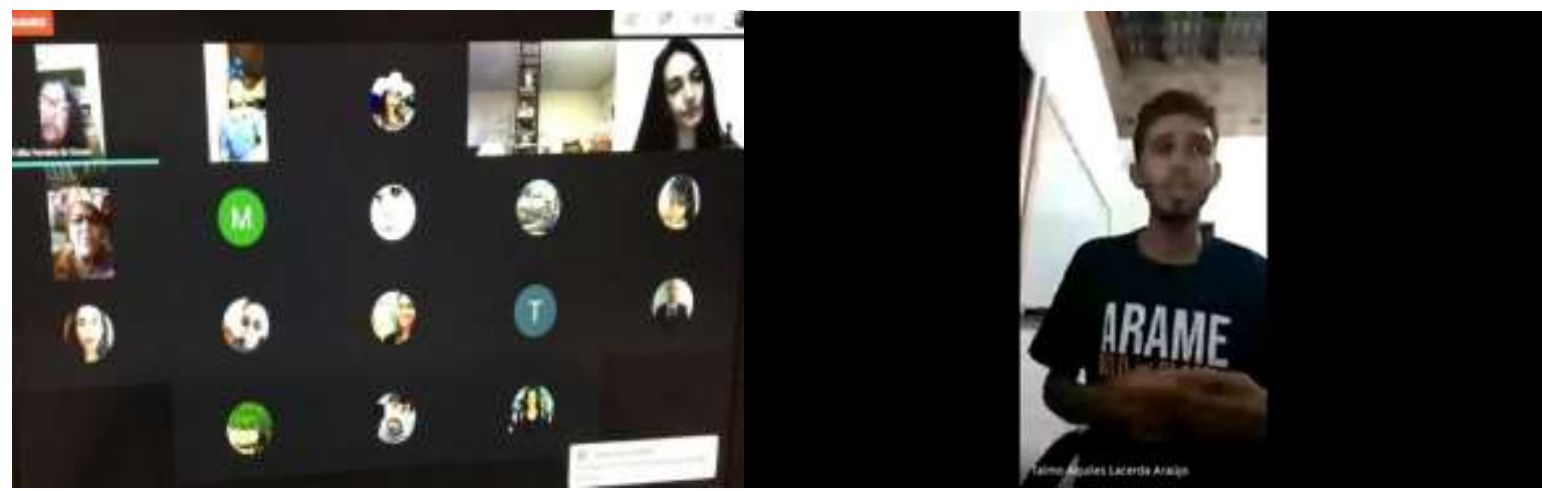

Fonte: arquivo das autoras, setembro de 2020.

Figura 03-oficina sobre artes cênicas-02 encontros

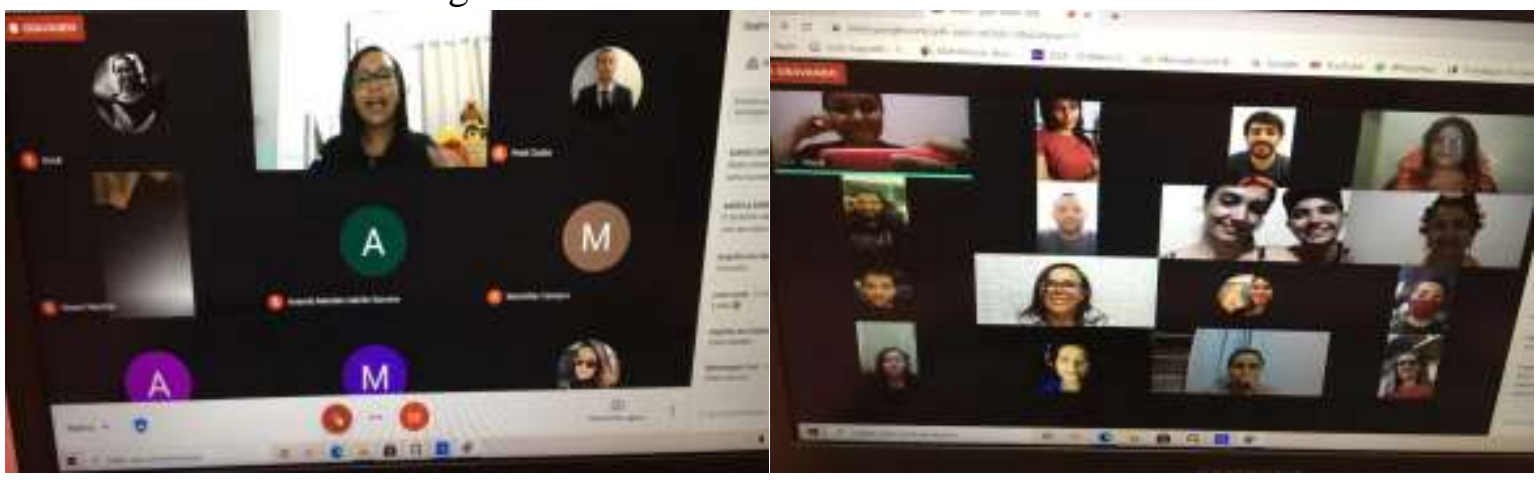

Fonte: arquivo das autoras, setembro de 2020.

Sendo assim, o desenvolvimento dessa célula/curso de extensão de aprendizagem cooperativa tendo o teatro como foco, equivale também ao reconhecimento de que o contato com a linguagem teatral ajuda tanto nós enquanto acadêmicos, como também as crianças e os adolescentes da educação básica que estão vinculados ao nosso projeto/Células. Pois a ideia é que a partir dessa célula os mesmos possam aos poucos irem perdendo a timidez, aprendendo a priorizar a noção do trabalho em grupo, uma vez que a prática de solidariedade entre os membros da célula faz com que os mesmos desenvolvam habilidades para se saírem bem de situações, em que é exigido o improviso, podendo de tal modo, fazer com que todos tenham maior interesse por ler textos literários, bem como conhecer com mais profundidade autores e obras que abordam a questão das artes cênicas. 
Não podemos perder de vista que o teatro privilegia o uso da linguagem e favorece o desenvolvimento da imaginação filosófica e artística. Por isso, nesse momento de pandemia é tão importante o uso das tecnologias. Muitos alunos estão conhecendo esse "mundo virtual" sobre outra perspectiva, deixando de fazer uso da internet apenas para interação entre amigos, mas também para o desenvolvimento pessoal e melhoria das condições de aprendizagem. Tal perspectiva nos remete a concepção de educador posta por Candau (2011), a qual afirma que:

[...] o novo educador é aquele que encara a educação como problematização. A educação assim encarada é aquela que propicia desenvolver nos alunos o seu poder de captação e compreensão do mundo como realidade em processo, pensando-o e a si mesmo, sem dicotomizar este pensar da ação. A prática educativa problematizadora propõe aos homens a sua própria situação como um problema (um desafio) a ser encarado, visando à transformação, (CANDAU, 2011, p.102).

A luz da concepção de Candau (2011), asseguramos que esse novo educador está em frente com um, também novo, modelo de ensino. Sendo assim, a modalidade educacional denominada de ensino remoto por ser desenvolvida através das plataformas digitais tem sido um desafio para alunos e professores. Por isso, o educador deve buscar metodologias que proporcionem um efeito de aprendizagem significativa, onde os alunos se tornam sujeitos protagonistas. Assim, podemos afirmar a importância da realização de atividades que motivam professores e alunos a refletirem sobre as suas competências e habilidades, bem como aprender reconhecer as suas limitações.

A nossa compreensão em relação ao ensino remeto sustenta-se na concepção dos autores Garcia, Morais, Zaros e Rêgo (2020, p. 04), por entendermos que “[...] é reconhecível que o ensino remoto comporta potencialidades e desafios, que envolvem pessoas, tecnologias, expertise e infraestrutura [...]". Ressalvamos ainda que para esses autores:

[...] ensinar remotamente não é sinônimo de ensinar a distância, embora esteja diretamente relacionado ao uso de tecnologia e, nesse caso, digital. O ensino remoto permite o uso de plataformas já disponíveis e abertas para outros fins, que não sejam estritamente os educacionais, assim como a inserção de ferramentas auxiliares e a introdução de práticas inovadoras. A variabilidade dos recursos e das estratégias bem como das práticas é definida a partir da familiaridade e da habilidade do professor em adotar tais recursos. 
Em um dos nossos encontros virtuais, do mês de setembro (2020), refletiu-se sobre essa questão, no momento em que um dos palestrantes falou sobre a importância dos professores e alunos se colorem na condição de serem parceiros na construção de novas estratégias para enfrentarmos os desafios posto pela condição de isolamento, onde a educação e arte não podem parar. Em que a lógica da abordagem direcionava para o entendimento que a construção de sentido para a história do lugar tendo como referência as manifestações culturais:

[...] Olhar para o outro e me preocupar com outro é essencial. Eu também preciso permitir que o outro me olha, mas este olhar para mim não pode se tornar uma barreira. Eu estou rompendo com essa lógica do extrativismo, essa lógica da arte na vida. Então eu, faço um convite um para a gente pensar o cooperativismo como sendo o modo de olhar, nós olharmos para nossas mentes, olhar para as coisas esquisitas que nós temos, olhar para as nossas estranhezas. Perceber esses elementos do outro de maneira diferente e assim, estaremos vendo a interligação das coisas na dimensão da arte, na experiência da arte trabalhando com teatro nas escolas onde eu estou trabalhando. Eu tenho levado à conclusão que a arte através do cooperativismo, ela trabalha com quatro elementos do ser. $O$ primeiro elemento é que ela trabalha em mim, trabalha em nós a dimensão da afetividade e da sexualidade e o segundo elemento é que ela trabalha a dimensão da vida em grupo e o terceiro elemento é que ela trabalha dimensão da vida em sociedade e o quarto elemento que é o que nos lança para frente, ela está com a dimensão do projeto de vida (trecho da fala do professor João Marcos - ministrante de uma oficina realizada em setembro de 2020).

Tal perspectiva nos remete a concepção de Leontiev (2000, p. 144), ao enfatizar que a "arte orientada para o desenvolvimento pessoal quebra normas e clichês, confere novos significados e novas maneiras de ver e de avaliar a realidade". Ou seja, a arte enquanto teatro nos ensina a fazer bom proveito dos nossos sentidos, da nossa sensibilidade e, assim, compreender o mundo sob outro olhar, tomando consciência da realidade e das mudanças que o mundo necessita.

Corroborando com essa concepção Vygotsky (1999, p. 315-316), assegura que “[...] a arte é social em nós, e, se o seu efeito se processa em um indivíduo isolado, isto não significa, de maneira nenhuma, que as suas raízes e essência sejam individuais. [...] O social existe até onde há apenas um homem e as suas emoções pessoais". “[...] A arte introduz cada vez mais a ação da paixão, rompe o equilíbrio interno, modifica à vontade em um sentido 
novo, formula para a mente a revive para sentimento aquelas emoções, paixões e vícios que sem ela teriam permanecido em estado indefinido imóvel[...]."

Na Filosofia, Courtney (1980), diz que Aristóteles e Horácio foram os autores das bases para o pensamento humanista no teatro. O primeiro, na sua Poética, já afirmava que a imitação é natural ao homem e que o ser humano aprende por meio dela; o segundo, por sua vez, em Arte Poética, considerava que o teatro deveria tanto entreter quanto educar. Portanto, mesmo com tantas vertentes de pensamentos, o teatro é considerado como sendo um meio necessário para se conseguir o desenvolvimento dos alunos e buscar a aprendizagem através da participação e interação entre os mesmos.

Courtney (2003) refere ao ensino do teatro dizendo que,

[...] a Expressão Dramática é não apenas o modo de encarar o processo educacional (uma filosofia), ou o modo de ajudar o desenvolvimento individual (uma psicologia) ou assistir o indivíduo em sua adequação ao meio (uma sociologia); é a maneira fundamental na qual o ser humano aprende - e, assim, é o mais efetivo método para todas as formas de educação, (COURTNEY, 2003, p. 278).

O teatro é essencial, enquanto componente curricular, porque desenvolve a comunicação e prepara o aluno para a sociedade por ser uma arte, onde envolve a aprendizagem social que muda a realidade vivida, mas não deixa de compreendê-la. Isto é, por meio do teatro o aluno terá sua sensibilidade artística aguçada, buscando mudanças ao seu redor.

Por esse motivo é tão importante que a escola crie momentos propícios para o "fazer artístico", onde alunos e professores possam se aprofundar na arte de modo a desenvolver o lado humano e o conhecimento da história em geral. Augusto Boal (1998), teatrólogo brasileiro, diz que o teatro é "[...] uma forma de conhecimento e deve ser também um meio de transformar a sociedade. Pode nos ajudar a construir o futuro, em vez de mansamente esperarmos por ele" (BOAL, 1998, p. 11).

Entretanto, fazer acontecer esse momento na atual conjuntura que vive o Brasil, devido à pandemia é ainda mais desafiador. Por isso, é importante saber fazer uso correto dos recursos tecnológicos, buscando se informar e aprender cada vez mais sobre as mais diversas plataformas digitais, onde a aprendizagem cooperativa possa ser trabalhada de forma leve e enriquecedora. 
Tal como já foi dito antes, com esse curso de extensão tínhamos a pretensão de fazer proveito das possibilidades do ensino remoto, superando a crise pela qual o país vive e, assim o fizemos. A educação a distância não é novidade, mas diante a Covid-19, os professores dos diferentes níveis (Básico e Superior), têm buscado estratégias para superar os desafios. Para não suspender as atividades de aprendizagem foi preciso manter as aulas remotamente.

Dessa forma, o curso de extensão buscou trabalhar o teatro de forma leve e agradável para que a aprendizagem ocorresse como planejado, exercendo sempre a cooperatividade entre os cursistas; pois,

[...] o teatro oferece, por ser uma atividade grupal, o exercício das relações de cooperação, diálogo, respeito mútuo, reflexão sobre como agir com os colegas, flexibilidade de aceitação das diferenças e aquisição de sua autonomia como resultado do poder agir e pensar sem coerção, (BRASIL, 1998, p. 84).

A socialização é uma das principais características da aprendizagem cooperativa, o prazer que os estudantes sentem ao estudar a arte traz como resultado o companheirismo e o respeito entre eles. Pois segundo Lopes (1999), torna-se necessário estruturar projetos com continuidade que acompanhem a criança e o jovem no percurso da descoberta e do desenvolvimento harmonioso e que o dotem de memórias e ferramentas válidas para o exercício saudável da cidadania.

Desse modo fez- se necessário criar espaço/ambiente (virtual) para acontecer o conhecimento mútuo, fazendo contribuições saudáveis para o desenvolvimento de cada cursista. Claro que o teatro como componente curricular, enquanto conteúdo e recurso é essencial para potencializar o campo científico, no que refere à qualidade do ensino, trabalhando os sentidos, o corpo e a imaginação dos estudantes, tendo como resultado a criatividade.

Portanto, esse trabalho partiu da experiência do curso de extensão -Teatro como Componente Curricular e a Aprendizagem Cooperativa no Contex to das Ações do Programa FOCCO, partindo do princípio de que a educação precisa ser trabalhada nas diversas formas e linguagens, sendo elas verbais e não verbais (onde se inclui a linguagem corporal) oferecendo aos cursistas melhores oportunidades de ensino/aprendizagem.

Os desafios não são somente o de ensinar e aprender. Os exercícios vão além. É necessário ter diferentes conteúdos curriculares para mediar com a tecnologia, para que 
assim os estudantes aprendam. Talvez a questão do tempo tenha sido a primeira reflexão promovida pela impossibilidade da aula presencial: foi preciso (e ainda está sendo necessário) rever a relação com os "tempos de aula" (ARROYO, 2013).

O curso ainda se encontra em andamento, mas no momento os resultados já são positivos. Pode-se afirmar então que, mesmo com os desafios do ensino remoto, os objetivos estão sendo alcançados positivamente. É visível que as atividades que estão sendo desenvolvidas pelos cursistas têm contribuído para potencializar suas habilidades e reforçam o aprendizado, porque o teatro é conforme Wánely Felício afirma,

[...], tem um papel importante na vida dos estudantes, uma vez que, sendo devidamente utilizado, auxilia no desenvolvimento da criança e do adolescente como um todo, despertando o gosto pela leitura, promovendo a socialização e, principalmente, melhorando a aprendizagem dos conteúdos propostos pela escola, (FELÍCIO, 2009, p. 176).

O mundo em torno do aluno é refletido na sua sensibilidade criativa, por isso o teatro é uma experiência de grande valor, porque engloba a realidade do indivíduo em sociedade, compreendendo os valores culturais, morais e éticos.

\section{Perfil dos cursistas - curso de extensão o teatro como componente curricular e a aprendizagem cooperativa no contexto das ações do programa FOCCO}

$\mathrm{Na}$ expectativa de conhecer o perfil dos cursistas aplicamos um formulário online, pelo qual perguntamos sobre: gênero, idade, onde mora e grau de escolaridade. De acordo com as respostas obtidas percebemos que: $26,7 \%$ são do sexo masculino e $73,3 \%$ feminino; a idade dos cursistas é de 15 a 40 anos; moram na região do Araguaia, em outras regiões do estado de Mato Grosso e também fora de Mato Grosso; e o grau de escolaridade é de $2 \%$ para o ensino fundamental, 16\% para o ensino médio, 33\% para o ensino superior incompleto, $31 \%$ para o ensino superior completo, $16 \%$ com especialização, $2 \%$ mestrado e $2 \%$ doutorado.

Buscando ainda conhecer mais sobre o perfil dos cursistas indagamos; se moram com a família, se tem acesso à internet, por qual dispositivo móvel acessam a internet com mais frequência e se conseguem fazer download de documentos. Obtivemos as seguintes respostas: $77,8 \%$ moram com a família e $22,2 \%$ não; $98,9 \%$ tem acesso à internet e 1,1\% 
não; para dispositivos que mais usam para acessar a internet $51,1 \%$ celular, $6,7 \%$ computador e 42,2\% ambos; e $81,1 \%$ conseguem fazer download, $0 \%$ não e 18,9\% ás vezes.

Posteriormente, questionamos também sobre: a velocidade da rede para baixar vídeos e áudios, grau de dificuldade em participar de cursos online e se gostam de atividades culturais, onde obtivemos as seguintes respostas: 77,8\% consegue baixar áudios e vídeos com rapidez, 2,2\% não e $20 \%$ ás vezes (depende do tamanho do arquivo); no que se refere ao grau de dificuldade em participar de cursos online, 38,9\% alegaram ter extrema dificuldade, $1,1 \%$ asseguraram não ter nenhuma dificuldade, enquanto $60 \%$ variaram em torno de dificuldade razoável ou mais ou menos. E 97,8\% gostam de atividades culturais e 2,2\% declararam não gostar.

Quando perguntado sobre quais atividades culturais são realizadas na escola em que estuda ou trabalha, as respostas mais frequentes foram: a) atualmente não estou participando de nenhuma, porém ano passado participei de algumas[...], mas todas voltadas ao curso que eu faço (Letras- português/espanhol); b) música, dança, teatro, recitação de poesia; c) Cultura da região; d) amostra literária; e) sarau literário; f) festival de teatro e dança; g) noite cultural; $h$ ) atividades esportivas.

Procuramos também saber qual era a importância do teatro para a educação, obtivemos como respostas: a) é muito importante, tendo em vista que é uma das maneiras mais rápidas de aprender, principalmente para a educação infantil e infanto-juvenil; $b$ ) o teatro é de extrema importância para a educação, pois a sua prática propicia o estimulo e desenvolvimento de várias habilidades e potencialidades, como criação, sensibilidade, interpretação, desenvoltura, além de gerar socialização e integração; c) tem grande relevância para conhecimento da cultura teatral e entretenimento; d) Projetos anuais e em especial a festa da colheita que acontece todos os anos; e) é muito importante para o desenvolvimento da criança e motivador; f) desenvolvimento da oralidade e interação.; $g$ ) o teatro é importante para aguçar a sensibilidade do aluno, melhorando sua capacidade de concentração bem como memória.

$\mathrm{Na}$ tentativa de saber qual é o papel do teatro na sociedade, na visão dos cursistas, as respostas obtidas foram: a) creio que seja uma maneira de expressar, colocar suas ideias sobre determinados assuntos de uma maneira mais sútil..., b) o teatro é de extrema importância para a educação, pois a sua prática propicia o estimulo e o desenvolvimento 
de várias habilidades e potencialidades, como criação, sensibilidade, interpretação, desenvoltura, além de gerar socialização e integração...,c) de levar cultura, alegria e conhecimento..., $d$ ) ajudar a desenvolver a leitura e a interação entre os participantes....,e) promover a interação trabalhar...,f) valorização da cultura...,g) criatividade, coordenação motora, vocábulos, desenvolvimento perceptivo, perda da timidez...

Ao serem questionados sobre quais são as expectativas em relação ao curso de teatro, as principais respostas: a) estou "super" na expectativa, gosto muito de falar, expressões corporais, movimentos, da fantasia..., b) altíssima! ..., c) espero que tal curso possa contribuir para os meus estudos na área, assim como propiciar conexões com mais pesquisadores, pensadores e artistas..., c) ótima..., d) alegria de aprender algo que poderei fazer os outros sorrirem..., e) é pensar sobre um determinado assunto com calma e felicidade apesar de todas as dores apresentar pela problemática..., g) incentivar os jovens, crianças e adultos..., h) aprender mais...i) melhorar a minha oralidade e interação com outras pessoas.

Os resultados obtidos sinalizam a importância de darmos voz aos cursistas, e que as atividades universitárias por meio de curso de extensão é uma estratégia eficaz no sentido de promover uma maior aproximação da universidade com a sociedade, e do modo em geral os cursistas, avaliaram a influência do teatro no currículo escolar como sendo um recurso que proporciona uma melhor qualificação nas atividades propostas pelos projetos de aprendizagens.

\section{Considerações finais}

O teatro é indispensável enquanto componente curricular, porque possibilita a interação através das expressões artísticas de cada aluno e, também, dos professores. É também essencial para a construção da aprendizagem, a partir do estímulo de exercícios que trazem maior absorção de conhecimento, contribuindo para formar "mentes" expressivas e criativas.

Ao tomarmos como referência as experiências que estamos vivenciando, concluímos que o teatro estabelece uma ligação com a vida. E trabalhar o teatro através da aprendizagem cooperativa é também uma forma de praticar a cidadania, visto que, os alunos têm a liberdade 
para usar a sua criatividade através de escolhas que dizem respeito a sua realidade, a sua forma de enxergar o mundo.

Enfim, o trabalho com o teatro precisa ser concebido como algo que esteja para além da condição de ser desafiador. O educador, principalmente agora nesse momento de ensino remoto, deve buscar trabalhar ainda mais o potencial que cada aluno já possui. No decorrer das atividades do curso foi possível perceber o avanço de conhecimento dos cursistas, a melhoria na forma de se expressarem através de oficinas, nos comentários e nas dinâmicas das atividades, mesmo sendo na modalidade de aulas virtuais. Sendo assim, esperamos por um resultado final ainda mais satisfatório.

\section{Referências}

ARROYO, Miguel González. Currículo, território em disputa. 5. ed. Petrópolis/RJ: Vozes, 2013.

BERTHOLD, MARGOT. (1996) História mundial do teatro. Tradução de Maria Paula Zurawski, J.Guinsburg, Sérgio Coelho e Clóvis Garcia. 3. ed. São Paulo: Perspectiva

BOAL, A. Jogos para Atores e não Atores. 14. ed. Rio de Janeiro: Civilização Brasileira, 1998. Notas preliminares, p. XX.

BRASIL, Ministério da Educação. Parâmetros Curriculares Nacionais Artes. Vol.6. Brasília, DF: 1998.

CANDAU, Vera Maria (org.). Rumo a uma Nova Didática. Petrópolis: Vozes, 2011.

CANDAU, Vera Maria (org.). A Didática em Questão. Petrópolis: Vozes, 2011.

COURTNEY, R. (1980). Jogo, Teatro e Pensamento. São Paulo: Editora Perspectiva.

COSTA, A.C.G. A presença da Pedagogia: teoria e prática da ação socioeducativa. $2^{\text {a }}$ ed. São Paulo: Global: Instituto Ayrton Sena, 2001

FREIRE, Paulo. Pedagogia do Oprimido. 41. ed. Rio de Janeiro: Paz e Terra, 2005.

FREIRE, Paulo. Pedagogia da autonomia: saberes necessários à prática educativa. 37. ed. São Paulo: Paz e Terra, 1996.

GARCIA, Tânia Cristina Moreira; Et al. Ensino Remoto Emergencial proposta de design para organização das aulas. Disponível em: https://www.progesp.ufrn.br/storage/documentos/4ANZamKLBv08IIEfMZcpaUCUZ6p8 WConk8nCNEMe.pdf. >Acesso em 10/10/2020. 
LEONTIEV, D. A.(2000), "Funções da Arte e Educação Estética". In FRÓIS, (coord.) Educação Estética. Abordagens Transdisciplinares (pp.127-145). Lisboa: Fundação Calouste Gulbenkian.

LOPES, José e SILVA, Helena Santos. A Aprendizagem Cooperativa na Sala de Aula: um guia prático para o professor. Lisboa/Portugal: Lidel - Edições Técnicas, 2009.

LOPES, M. Texto e criação na escola. Porto: Asa Editores, 1999.

SILVA, K. V.; SILVA, M. H. Dicionário de conceitos históricos. 2. ed., 2. Reimp. São Paulo: Contexto, 2009.

VYGOTSKY, L. S. Psicologia da Arte. Tradução de Paulo Bezerra. São Paulo: Martins Fontes, 1999. 